\title{
TRAVESSIAS, DESLOCAMENTOS: APONTAMENTOS SOBRE A ESCRITA MIGRANTE EM O FILHO DA MÃE, DE BERNARDO CARVALHO
}

\author{
Paulo César Silva de Oliveira (UERJ)
}

Resumo: Este artigo parte de uma leitura crítica do romance $O$ filho da mãe, de Bernardo Carvalho (2009), que tem como foco duas imagensforça construídas pela obra, as do kunak e da quimera. Nossa reflexão se estabelece em um campo crítico-conceitual que toma como referência a escrita migrante na narrativa contemporânea em diálogo com o conceito de cronotopo estabelecido por Mikhail Bakhtin e com as discussões oriundas do pensamento de Walter Benjamin, Lucia Helena e Zygmunt Bauman, dentre outros. Os movimentos de travessia e deslocamento no mundo da globalização de fábula, conforme pensou Milton Santos (2000), nos levam a pensar o campo literário como um movimento de passagem por onde diversos saberes cooperativos circulam: literatura, sociedade, representação, história e política.

Palavras-chave: Trânsito; Narrativa; Bernardo Carvalho; O filho da mãe; Teoria.

Abstract: The reading of Bernardo Carvalho's $O$ filho da mãe (2009), according to two force-images, of the kunak and the chimera, is the starting point of this article, which aims to establish a critical and conceptual reading on the topic of the migrant writing in the present. Focusing on the concepts of chronothrope (Mikhail Bakhtin), and with the lateral help of Walter Benjamin, Lucia Helena and Zygmunt Bauman, among others, the article investigates the processes of crossing and displacement in the world of the globalized fable described by Milton Santos (2000). The literary field is here understood as a movement of passage through which diverse cooperative knowledge circulates: literature, society, representation, history and politics.

Keywords: Crossing; Narrative; Bernardo Carvalho; O filho da mãe; Theory. 


\section{INTRODUÇÃO}

Certos momentos históricos são marcados por algumas dominantes. Em nossa época, o problema dos sujeitos migrantes, a questão do trauma, das diásporas, dos deslocamentos forçados, das fugas individuais ou coletivas, de sujeitos em risco certamente são algumas delas. Arriscarse é um verbo reflexivo persistente nesses tempos estranhos. A literatura não é imune a essas questões, ao contrário, ela as toma como linhas de força da representação artística, especialmente no romance. Esta reflexão trata de uma dessas espécies romanescas, que aqui nomearemos de escrita migrante, exemplificada através de uma leitura do romance $O$ filho da mãe, de Bernardo Carvalho (2009).

O filho da mãe foi uma das obras mais aguardadas de um controvertido projeto intitulado "Amores Expressos", cuja proposta era a de levar alguns escritores brasileiros a diferentes cidades do planeta, onde se estabeleceriam por alguns meses, e de onde voltariam com a missão/obrigação de em um ano finalizar uma narrativa ficcional cujo tema privilegiado seria história de amor e a ação no espaço geográfico da cidade visitada. Deste projeto, participaram escritores já consagrados como Luiz Ruffato (Lisboa), Sérgio Sant'Anna (Praga) e Bernardo Carvalho (São Petersburgo); 
alguns em vias de consagração, como Daniel Galera (Buenos Aires), Joca Reiners Terron (Cairo) e João Paulo Cuenca (Tóquio), além de nomes ainda pouco conhecidos do público, como Chico Mattoso (Havana), Daniel Pellizari (Dublin), Paulo Scott (Sidney) e Amílcar Bettega (Istambul), dentre outros.

O propósito da empreitada foi o de aliar a questão da experiência vivida ao processo de criação ficcional. Os romances aprovados seriam publicados pela editora associada ao projeto - a Companhia das Letras - que por contrato se reservou o direito de escolha sobre o que publicar. Não foi o caso de $O$ filho da mãe, efetivamente lançado pela editora em 2009. Destaque-se que Carvalho já era escritor editado pela Companhia das Letras e tem, até o momento, todos os seus romances lançados pela casa. Com mais esta obra, Carvalho dá continuidade a uma série de narrativas, principalmente a partir de Nove noites, particularmente feliz.

Escritores migrantes, viajantes não são necessariamente um fenômeno de nossos tempos de globalização. $\mathrm{Na}$ modernidade, o romance ganha protagonismo e, embora seja difícil localizar origens, uma forma originária ${ }^{1}$ pode ser vislumbrada em certos momentos históricos.

1 O termo "originário" foi apropriado do pensamento de Martin Heidegger. Logo no início da conferência intitulada A origem da obra de arte, Heidegger define o Ursprung (o originário) como aquilo a partir de onde e através do qual algo é o que é e como é. Como nosso objetivo não é desenvolver o conceito neste trabalho, remeto à leitura de: HEIDEGGER, Martin. A origem da obra de arte. Lisboa: Edições 70, 1977. 


\section{Em "The Preface" a Moll Flanders, de Daniel Defoe (19-,} p.v), escrito por um suposto autor, em 1683 (Moll Flanders é publicado em 1722), já se lia:

The world is so taken up of late with novels and romances, that it will be hard for a private history to be taken for genuine, where the names and other circumstances of the person are concealed, and on this account we must be content to leave the reader to pass his own opinion upon the ensuing sheet, and take it just as he pleases.

The author is here supposed to be writing her own history, and in the very beginning of her account she gives the reasons why she thinks fit to conceal her true name, after which there is no occasion to say any more about that.

It is true that the original of this story is put into new words, and the style of the famous lady we here speak of is a little altered; particularly she is made to tell her own tale in modester words that she told it at first, the copy which came first to hand having been written in language more like one still in Newgate than one grown penitent and humble, as she afterwards pretends to be. ${ }^{2}$

2 O mundo está tão ocupado com romances e novelas que será difícil uma história particular ser considerada genuína, onde nomes e outras circunstâncias da pessoa são ocultados e, por isso, devemos nos contentar em deixar o leitor dar sua própria opinião sobre as páginas que seguem e tomá-las da maneira que lhe agrada.

A autora supostamente está escrevendo sua própria história e logo no início de seu relato ela dá as razões pelas quais acredita que é apropriado esconder seu verdadeiro nome e, após, não haverá mais tempo para dizer algo mais sobre esse assunto.

É verdade que o original desta história está posto em novas palavras e o estilo da famosa senhora de quem aqui falamos está um pouco alterado; especialmente, fizemo-la contar sua história em palavras mais contidas das que as que ela havia usado a princípio; a cópia que veio inicialmente cair em nossas mãos foi escrita em uma linguagem mais parecida com a de qualquer egresso de Newgate do que com a de uma humilde penitente, como ela dava a entender que seria mais tarde (Tradução nossa). 
O narrador de Defoe trata de uma personagem cuja trajetória de vida já havia sido resumida no extenso paratexto que é o título da obra, de que Moll Flanders é uma redução. Neste título, o leitor saberá que se trata das venturas e desventuras de uma senhora ao longo de 60 anos de vida: sua infância; doze anos como prostituta; uma passagem pela prisão de Newgate (situada em Londres e demolida em 1902); e a deportação para a Virgínia, colônia britânica na América do Norte, onde ela residiu por oito anos, fez fortuna e viveu, honestamente e arrependida. A própria Flanders relata esses episódios, mas o leitor verá que o jogo ficcional da narrativa autodiegética esconde o autor, que se imiscuiu na história como a dizer que é ele o titereiro a manusear os fios das aventuras protagonizadas pela personagem-fantoche.

Neste breve prefácio e através da personagem Moll Flanders, Defoe está nos revelando uma espécie nova de autor: o viajante, o empreendedor que transforma a experiência em discurso ficcional, o que Mikhail Bakhtin (2018, p.11) chamou de "processo de assimilação do tempo e do espaço reais, e do homem histórico e real que neles se revela" e que transcorre "de forma complexa e descontínua". Interessa-nos entender o cronotopo bakhtiniano como "categoria de conteúdo-forma da literatura" (BAKHTIN, 2018, p.11), que na obra de Bernardo Carvalho enxergamos como modo de entrada em sua poética. 
Ao tratar de dois tipos essenciais de autobiografia clássica, Bakhtin situa uma primeira forma de consciência na Apologia de Sócrates e no Fédon, ambos de Platão, os quais descortinam uma escrita do caminho direcionada ao verdadeiro conhecimento, de si e do mundo. Quanto ao segundo tipo de autobiografia, Bakhtin (2018, p.73) o situa na relação estabelecida pelos gregos entre o autobiográfico e o biográfico que se funda no encômio: "discurso civil de homenagem proferido ao pé do caixão, que substitui à antiga "lamentação" (threnos)", apontando para a relação entre "acontecimento político-social concreto" associado à publicação ruidosa desses discursos. Bakhtin mostra como a autobiografia e o incipiente mercado grego se configuram no espaço público da praça (ágora) por meio de uma práxis que revela um sistema de relações sociais complexas no qual se desnuda "a total exterioridade do homem clássico e de sua vida" (BAKHTIN, 2018, p.76). A desintegração dessa exterioridade pública se daria por meio de uma terceira forma, marcada essencialmente pelo solilóquio, no qual se manifestaria a "autoconsciência do homem solitário" em relação a si mesmo e "sem concessão de voz a um "terceiro", independentemente de quem ele seja" (BAKHTIN, 2018, p.88). Neste terceiro tipo de modificação, pesam os acontecimentos da vida íntima, pessoal, 
mas a relação público-retórica permanece, encerrando um período histórico identificado pelas "formas basilares da autobiografia antiga e da biografia" (BAKHTIN, 2018, p.90).

$\mathrm{Na}$ passagem da Idade Média para o Renascimento e deste para as formas modernas de narração, o romance certamente recolhe, refaz e reinstitui estéticas antigas, devolvendo-as ao leitor sob a forma do cronotopo. Em Daniel Defoe, as formas do biográfico e do autobiográfico se hibridizam de tal forma que só resta à autoconsciência narrativa expor ao leitor os meandros da história contada por um primeiro outro (a personagem Moll Flanders) cuja voz é modificada por um segundo outro (o narrador que diz explicitamente que interfere na narrativa original, atenuando ou apagando certas formas que considera inadequadas ou insuficientes à narração). O autor será também identificado como uma espécie de outro dentro da obra, que a escreve com distanciamento fingido, pois a relação entre experiência pessoal e o que se ficcionaliza é mediada por um discurso que, ao contrário da autobiografia antiga, não dá conselhos, não aponta um modus vivendi, não se torna encomiástico e nem desconhece a relação entre o eu que narra e o outro narrado: ao contrário, confunde e dissipa essas dicotomias, arrastando-as para um lócus indiferenciado. 
Queremos estudar esse lugar onde são encenadas as relações entre a escrita migrante de Bernardo Carvalho e o mundo social representado em seu $O$ filho da mãe. Neste sentido, novamente recorrendo a Bakhtin, veremos que

o heterodiscurso introduzido no romance (quaisquer que sejam as formas de sua introdução) é discurso do outro na linguagem do outro, que serve à expressão refratada das intenções do autor. A palavra de semelhante discurso é uma palavra bivocal especial. Ela serve ao mesmo tempo a dois falantes e traduz simultaneamente duas diferentes intenções: a intenção direta da personagem falante e a intenção refratária do autor. (BAKHTIN, 2015, p.113 - grifos do autor)

A essas relações, acrescentamos um viés políticosocial, que chamaremos de "texto crítico do mundo", que na narrativa ficcional se estabelece entre as relações intratextuais e a exterioridade mundana. Nestas relações subjazem os processos de deslocamento na esfera da globalização, incidindo no campo individual, dos afetos e das subjetividades de indivíduos expostos a guerras, a processos diaspóricos e traumáticos, que enfrentam em seus locais de origem uma série de ameaças a seu modo de ser e estar no mundo. São sujeitos amaldiçoados por conta de escolhas e desejos; são híbridos monstruosos, quimeras. Neste sentido, diáspora e deslocamento são termos correlatos e sinônimos 
de uma monstruosidade de origem, marca do mal, quase sempre ligado ao horror à diferença. No romance, trataremos dos modos com que a "intenção refratária" de Carvalho se revela na "intenção direta do falante", traduzindo processos bivocais, duplas articulações autor/narrador; texto/mundo; leitor/autor; escrita/leitura.

\section{A ESTETIZAÇÃO DA EXPERIÊNCIA}

O escritor americano David Leavitt disse em Arkansas (1998), na novela "The term paper artist", que os escritores frequentemente disfarçam sua vida na ficção, mas o que quase nunca fazem é disfarçar a ficção em suas vidas. Essa observação nos chama a atenção para alguns aspectos de uma nova/velha discussão sobre a literatura e o papel dos escritores no mundo do mercado globalizado e traz mais uma vez ao debate a antiga questão do caráter mimético da literatura. No debate aberto pelas obras do projeto "Amores Expressos", o recorrente tema do nacionalismo que, como bem expressou Leyla Perrone-Moisés (2007), "vira mexe" retorna, é reconduzido à cena crítica. Em uma sociedade globalizada, é de se esperar que conceitos como os de nação, nacionalismo e identidade se encontrem no centro das problematizações do mundo.

Em O filho da mãe, as escolhas crítico-estéticas de Carvalho amplificam algumas dessas questões. 0 "mundo 
crítico do texto" que o escritor vem construindo, obra a obra, dialoga com o "texto crítico do mundo" (OLIVEIRA, 2010) de nossa época histórica por meio de trânsitos ficcionais que nos importam considerar. Como veremos, na trama de $O$ filho da mãe, há alguns temas essenciais - com destaque para as questões de identidade, deslocamento e lugar do sujeito em tempos de economia planetária - essenciais à avaliação crítica dos processos ambíguos que enredam as vidas desperdiçadas e alijadas das agendas do capital. O tema da monstruosidade, identificado como uma chave de leitura do romance carvaliano alinhava questões bem resumidas na pergunta/provocação: viver em uma sociedade planetária significa o mesmo que viver em um mundo integrado, unificado, democratizado?

Na cena de abertura de $O$ filho da mãe, tomamos ciência do encontro de duas antigas amigas de escola, Marina Bóndareva e lúlia Stepanova, personagens estratégicas no desenvolvimento da narrativa central do romance. Após receber de seu médico a notícia da morte iminente, por conta de uma doença fatal, lúlia decide procurar o Comitê das Mães dos Soldados de São Petersburgo, entidade de ajuda aos jovens convocados para lutar na Guerra da Tchetchênia. Lá reencontra a antiga companheira de faculdade, Marina, 
agora uma das líderes desta associação. $\mathrm{O}$ fato de não ter tido filhos motiva lúlia a oferecer ajuda a algum jovem. A própria Marina é uma das vítimas da guerra. Seu filho se suicidara após ser convocado para lutar no conflito. Através desse encontro solidário, o leitor saberá da história dos jovens Ruslan e Andrei, personagens centrais do romance e cuja trajetória se entrelaça tragicamente com os dramas da guerra e das duas mulheres. $O$ reencontro dessas mulheres prenuncia, portanto, a emergência de outras histórias, como as do tchetcheno Ruslan e do russo Andrei.

Saberemos in ultima res que Andrei fora morto em uma missão nas montanhas ao sul de Grózni, quando os eventos mais importantes da trama já se encerraram. De Ruslan, teremos ciência nas primeiras páginas do romance de que é filho da russa Anna com o tchetcheno Chackban. Ruslan é abandonado pela mãe na Tchetchênia quando criança e deixado aos cuidados do pai e da avó, Zainap. Com a morte de Chackban na guerra, Zainap consegue, antes de morrer, levar o neto para fora do país, cruzando as fronteiras da Tchetchênia e ingressando na Rússia. Lá, Ruslan tenta contactar a mãe, ao mesmo tempo em que planeja fugir do território russo. É nesse contexto que Ruslan encontra Andrei, recém-convocado pelo exército russo. Andrei é forçado 
pelos oficiais superiores a se prostituir para levar dinheiro ao quartel. Quando Ruslan rouba a carteira de Andrei e leva do recruta o dinheiro oriundo da prostituição, a história dos dois se cruza e o romance se bifurca, passando ao duplo relato: por um lado, uma história de amor entre dois jovens envolvidos na guerra entre seus países e por outro, relato de mães e mulheres tentando desesperadamente salvar seus filhos e os de outras mulheres.

Uma voz heterodiegética predominante realça as relações bivocais que denotam a sombra do autor nas veredas do romance. É uma voz pouco frequente nos primeiros romances de Carvalho, mas vem ganhando força em suas obras mais recentes. Ela sustenta uma aparente adesão a técnicas narrativas de cunho mais realista, no entanto, como se vê no processo dialógico das narrativas romanescas, vão surgindo e se estruturando de forma a criar um mosaico de temas e reflexões particularizadas pelo autor, confirmando escolhas poéticas particulares. Uma narrativa mais direta, que opta por formas lineares de organização do cronotopo - sem as intensas hibridizações a que nos acostumamos em romances como Nove noites - também se deve, em parte, às demandas do projeto "Amores Expressos", de transformar os romances em potenciais roteiros cinematográficos. 
São aspectos do campo cultural que influem no campo literário determinando inclusive escolhas formais.

$\mathrm{Na}$ representação ficcional da Segunda Guerra da Tchetchênia predomina ora $\mathrm{o}$ tema da maternidade ora $\mathrm{o}$ relato da história de amor entre os dois jovens. Mas, uma terceira forma de compreender a história, mais abrangente e com maiores pretensões desvela elementos interpretativos que propiciam reflexões agudas sobre nosso tempo. $O$ filho da mãe é um romance sobre ruínas. Não sem razão, as imagens do amor se configuram em meio a prédios destroçados que representam paisagens de morte esculpidas por anos de guerra em áreas periféricas da cidade de Grózni. A fala de lúlia ao final do romance traduz bem os processos de clausura a que as personagens estão submetidas: "Ninguém quer ler o que está por vir, à beira do abismo. As pessoas precisam se agarrar ao que já conhecem. Os modernismos não podem mesmo durar. Nem as revoluções. Ninguém vai construir uma casa à beira do abismo" (CARVALHO, 2009, p.186).

Ao definir (e profetizar) tais histórias de amor por meio de lúlia, a obra nos sugere uma linha interpretativa: a modernidade descrita como uma casa à beira do abismo nos dá conta da falsa solidez em que o mundo contemporâneo se assenta. Conforme Giorgio Agamben (2009), devemos olhar 
a contemporaneidade da mesma forma como observamos o tempo que se esvai pelo retrovisor de um carro. Imersos em uma cultura do presente em que, ao mesmo tempo, vislumbramos um passado fugidio que insiste em se manifestar, vivenciamos o desenrolar de eventos em um aqui, agora e sempre, um continuum que privilegia o fluxo sem desconhecer o tempo passado. Nas observações de lúlia, o futuro é um tempo de impossibilidade que jamais chega: ele não basta nem se basta; se configura como promessa, vinda messiânica de um salvador (que talvez não salve). As histórias de amor na obra são passíveis de serem lidas como imagens de um mundo em ruína: portanto, uma poética $d a$ ruína estrutura nossa leitura do romance e sua arquitetura ficcional, expressa na fragmentação e nos discursos híbridos, além dos deslocamentos espaciais e temporais, que recortam um período compreendido entre os anos de 2002 e 2003.

A leitura da narrativa como poética da ruína possibilita uma visão aberta da história, que por não poder lidar com a totalidade se localiza nas fissuras do precário, como propôs Walter Benjamin, ao tratar do drama trágico:

A força determinante da forma histórica do tempo não pode ser totalmente apreendida por nenhum acontecimento empírico, nem absorvida completamente por ele. Um tal acontecimento, que seria perfeito no 
sentido da história, é antes um elemento empiricamente indeterminável, ou seja, uma ideia. A esta ideia do tempo preenchido chama-se na Bíblia - e esta é a sua ideia histórica dominante - o tempo messiânico. Em qualquer caso, a ideia do tempo histórico preenchido não é ao mesmo tempo a ideia de um tempo individual. É esta a determinação que, naturalmente transforma totalmente $o$ sentido desse preenchimento, que distingue o tempo trágico do messiânico. (2011, p.262)

Para Benjamin, um acontecimento não revela de imediato a compreensão da totalidade da forma histórica do tempo, já que entre o tempo histórico preenchido e o tempo individualmente preenchido impõe-se uma diferença: no tempo histórico preenchido (da ordem do messiânico) se estabelece um devir incessante; já no tempo histórico individualmente preenchido há consciência de que não se pode para sempre nele habitar, posto que somos finitos. Por isso, a "morte é uma imortalidade irônica", é "a origem da ironia trágica", em que "o mais pequeno passo em falso leva à culpa". Da mesma forma, "o mais ínfimo descuido, o mais inverossímil acaso acarreta a morte, quando todas as palavras do entendimento e da resolução dos conflitos [...] não são ditas", o que nos situa "perante aquela típica influência exercida pelo tempo do herói sobre todos os acontecimentos, porque no tempo preenchido todos os acontecimentos são função desse tempo próprio" (BENJAMIN, 2011, p.262). 
No universo de clausura do romance de Carvalho, o sujeito degradado em um mundo arruinado expressa o descompasso entre sua experiência individual e os horizontes do mundo por que transita. Essa é a matéria privilegiada pelo autor para criar uma ficção na qual um dos princípios unificadores da composição do romance pode ser percebido na coesão dos elementos abstratos dispostos que dá organicidade à trama: há uma espécie de poética da subjetividade criadora expressa na relação entre o mundo da experiência do autor e a realidade representada. Não significa que o romance seja um retorno à primeira forma de biografia antiga, grega, como vimos em Bakhtin, no sentido de um relato filosófico sobre a vida; nem à segunda, já que o discurso encomiástico não prevalece. Na verdade, nem mesmo haveria terceira forma, embora o mundo público e o mundo privado do autor sejam acessados. Isso se deve em grande parte às estratégias utilizadas pelo autor, que mantém o foco nas indissociações entre uma experiência fabricada e o texto literário dela resultante. Expliquemos.

Um recurso utilizado por Carvalho em seu processo ficcional é o blog, em que, sob as formas do diário, de crônicas, pequenos relatos, ele vai abastecendo o leitor com informações relativas aos rumos da escrita do romance. 
Assim, um assalto supostamente sofrido pelo escritor é elaborado em uma passagem do romance fazendo com que o leitor perceba a relação entre o evento e o assalto sofrido por Andrei. Conforme nos disse Mikhail Bakhtin (2015, p.109), os gêneros introduzidos no romance podem ser intencionais ou não, refratando em diferentes graus os objetivos do escritor: "As linguagens dos gêneros extraliterários que integram o romance ganham amiúde tal importância que a introdução de um gênero correspondente [...] cria uma época não só na história do romance, mas também na história da linguagem literária". O blog, certamente, introduz no escopo das relações entre texto e peritexto uma nova possibilidade de apreensão do discurso romanesco e do paratexto. Ao criar uma espécie de "diário de escrita" levado à exposição midiática via Internet, Carvalho altera o campo sintagmático da série literária ao inserir o elemento virtual, daí produzindo uma diferença no campo paradigmático, especialmente quanto à discussão da autoria.

A ética do herói diz respeito "sobretudo à configuração reflexiva do destino que cabe ao ideal na vida, à efetividade dessa relação com o destino e à consideração valorativa de sua realidade". Por isso, "ter de refletir é a mais profunda melancolia de todo o grande e autêntico romance" (LUKÁCS, 2000, p.86) e isso demanda do leitor uma participação efetiva, 
que vai além da leitura da trama. O leitor precisa buscar novas interpretações das formas de subjetivação do autor e do leitor nos processos que antecedem a construção final do texto - este organiza o horizonte de leituras e expectativas de modo a revelar o funcionamento do universo de saberes cooperativados. Esses fenômenos abrem o texto para novas possibilidades de análise pouco estudadas na recepção dos textos ficcionais.

Conforme Lukács já apontara, o romance tematiza uma investigação degradada e o individualismo que privilegia o sujeito em sua solidão no mundo da experiência não significa um elogio incontornável da exemplaridade. Walter Benjamin já nos mostrara que um dos exemplos da morte da experiência narrativa eram os relatos dos soldados que voltavam da guerra mudos de relatos. Já não sentamos em volta de fogueiras para narrar experiências e o romance é a arte que melhor reflete essa consciência do que se perdeu. O sujeito que habita o mundo de forma trágica tem a consciência tortuosa de não poder viver fora do mundo ou do tempo. $O$ mundo se impõe através de limites impostos previamente. Assim, a forma do trágico seria espectral, concentrada no limite e na repetição, no aspecto aberto de um jogo sem vencedores, cuja lição consistiria na consciência de que só podemos habitar o tempo histórico preenchido 
retardando o inevitável momento da catástrofe, em que a morte é a sanção do que se pode narrar.

Zygmunt Bauman dizia que no mundo da modernidade oblíqua, líquida, precisamos nos equilibrar entre o senso de comunidade e as liberdades individuais, tema caro a $O$ filho da mãe:

Em termos sociológicos, o comunitarismo é uma reação esperável à acelerada "liquefação" da vida moderna, uma reação antes e acima de tudo ao aspecto da vida sentido como a mais aborrecida e incômoda entre suas numerosas consequências penosas - o crescente desequilíbrio entre a liberdade e as garantias individuais. $O$ suprimento de provisões se esvai rapidamente, enquanto o volume de responsabilidades individuais (atribuídas, quando não exercidas na prática) cresce numa escala sem precedentes para as gerações do pós-guerra. Um aspecto muito visível do desaparecimento das velhas garantias é a nova fragilidade dos laços humanos (2001, p.195).

Bauman (1999, p.114) acredita que "o confinamento espacial, o encarceramento sob variados graus de severidade e rigor, tem sido em todas as épocas o método primordial de lidar com setores inassimiláveis e problemáticos da população, difíceis de controlar". Nessa zona turbulenta "se cultiva toda responsabilidade para com o Outro e o terreno de aprendizado para toda a ambivalência necessariamente 
contida na pressuposição dessa responsabilidade" (BAUMAN, 1998, p.90). Em meio a essa cena primordial partilhamos objetivamente da culpa pelo sofrimento e infortúnio humanos. Destarte, trata-se de uma política da responsabilidade em um mundo sem bússolas.

Dois fragmentos de $O$ filho da mãe servem como imagensforça, alegorias do mundo em crise. A primeira imagem é a alegoria do kunak; a segunda, a da quimera. O substantivo kunak vincula-se a um componente ético inserido na estrutura narrativa do romance e faz parte dos conteúdos manifestos na obra, tanto em relação à história das mães quanto em relação ao drama das personagens centrais, Ruslan e Andrei. O termo quimera problematiza as relações entre sujeito e mundo, o primeiro visto como malformação, "desvio" da "norma", o que equivale a dizer que representa a monstruosidade aos olhos das culturas e sociedades em que vivem.

A expressão kunak refere-se a um estrangeiro ou membro de um clã ou de uma tribo com quem se estabelece um pacto de proteção e fraternidade, conforme as tradições inguches (CARVALHO, 2009, p.39). Kunak era ainda a forma terna com que o pai de Ruslan o tratava quando criança. O termo possui um sentido ético conferido às personagens que sobrevivem 
em meio à clausura e à barbárie, de que a realidade da guerra e da opressão são exemplos. Os encontros clandestinos de Akif e Ruslan nos escombros de prédios bombardeados confirmam essa hipótese de leitura. A primeira relação amorosa de Ruslan é com Akif. Ela será marcada pela perda e pelo abandono, sentimentos que o acompanharão por toda sua curta vida. Estrangeiro em um mundo estranho, Ruslan entende que não somente a guerra, mas também as condições de sua existência na Tchetchênia são problemáticas: a guerra acentua o perigo de ser tchetcheno em meio ao violento domínio russo; já sua condição sexual o torna inadequado aos padrões sociais e comportamentais de sua pátria. Ruslan é duplamente inadequado: por um lado, por ser tchetcheno; por outro, por ser homossexual, Ruslan é, uma figura híbrida, espécie de quimera em um mundo que o delimita.

O sentido da monstruosidade será vivenciado por Ruslan na dupla qualidade de pátria, dentro e fora de sua terra. Ele próprio é uma representação da quimera, seja pela condição de homossexual, excluído em uma sociedade onde "qualquer tchetcheno a quem se fizer a pergunta dirá que não há homossexuais na Tchetchênia" (CARVALHO, 2009, p.35); na qualidade de tchetcheno, em meio a uma guerra contra o domínio russo. Acresce que nas tradições dos camponeses 
tchetchenos o híbrido é sinal de mau agouro, presságio de um mal só evitado pelo extermínio da quimera. Quimera pode significar "malformação de uma planta ou animal" "que se desvia do normal" ou um "objeto de grande tamanho e frequentemente assustador", "mau exemplo" etc. A figura da quimera alegoriza a monstruosidade, refletindo as tensões entre sujeito e mundo, o que denota uma subjetividade ameaçada que, na modernidade irregular e claudicante de certas regiões do globo, engrossam as fileiras da exclusão.

Ruslan e Andrei são estrangeiros em seus territórios. Modalidades do sentir-se estranho podem ser observadas no caso dos indígenas e dos sujeitos em áreas subjugadas ou no drama dos homens e mulheres expulsos de suas terras e dos sujeitos proibidos de professar suas religiões e crenças, sua sexualidade etc. A mobilidade dos que desfrutam de viagens aéreas não é a mesma dos que se arriscam nas travessias a barco e em fronteiras eletrificadas.

Se a Ruslan e Akif restou amar nos escombros, a representação literária da ruína expressa alegoricamente um tipo de pertencimento dos sujeitos à nação, conforme a entende Eric Hobsbawn (2013): um corpo suficientemente grande de indivíduos que se reconhecem pertencendo a um lugar seja por meio de procedimentos linguísticos 
ou pela partilha territorial. Essas noções se solidificaram na concepção de Estado-nação, mas já não dão conta das complexas políticas territoriais e de pertencimento.

O saber literário nos dá ensinamentos, e um deles diz respeito àquilo que extrapola a própria economia textual e se apresenta como aprendizagem. No caso do pertencimento, da exclusão, das políticas de amizade expressas na ideia do kunak e na noção de diferença como monstruosidade ou no exemplo da quimera a matéria ficcional cria lastros, retomando períodos literários distantes. No caso de 0 filho da mãe, o kunak tem correspondente no romantismo russo, pouco estudado entre nós. Em um fragmento do poema "Valerik", de Mikhail Lermontov $(2014)^{3}$, há relações intertextuais de interesse à compreensão da narrativa carvaliana:

A guerra acabou. Tudo estava imóvel.

Os corpos formavam uma pilha medonha.

O sangue gotejava, fumegante, esfumaçante...

'Só me diga, meu kunak,

Qual o nome desse riacho?'

'Chamam-no de Valerik', disse ele,

'Que quer dizer O Rio dos Mortos'

3 Mikhail Lermontov (Moscou, 1814 - Pyatigorsk, 1841) foi um dos mais importantes representantes do Romantismo Russo. Morto aos 27 anos, em um duelo, foi um crítico feroz de seu tempo e de sua sociedade. 
Os que o assim o chamaram estão no Céu...'

Então, a voz de alguém eu ouvi,

'Este é um dia decisivo para a guerra'.

Vi o escárnio no olhar do tchetcheno.

Ele sorriu forçadamente, mas não disse palavra. ${ }^{4}$

(Tradução nossa).

Lermontov foi testemunha da batalha entre tchetchenos e russos ocorrida nas proximidades do vilarejo de Valerik, na Tchetchênia, em 1840, ano em que compõe "Valerik". A história nos mostra que no século dezenove mais de 30 etnias se uniram para enfrentar o imperialismo russo. Pela lógica do suplemento, o texto literário ilumina os contextos extraliterários representados no poema de Mikhail Lermontov. Os discursos que rondam a obra artística aprimoram técnicas de leitura: é uma relação de mão dupla que recupera do passado elementos que fazem cintilar no presente uma verdade do mundo que de certa forma ficaria em segredo, mas que o romance, ao dizer "presente" aos fragmentos escondidos no passado, consegue reorganizar.

Ao estudarmos a figura da quimera, vemos que ela reclama saberes mitológicos, míticos e filosóficos que a suplementem.

4 No original em inglês: "The fight was over./ All was still./ The bodies made a grisly hill./ Blood trickled from them, steaming, smoking.../ 'Just tell me, my kunak,/ What do they call this little river?/ 'They call it Valerik', he said,/ 'Which means The River of the Dead./ Those who named it are in Heaven...'/ Then someone else's voice I heard,/ 'This day is for the war decisive'./ I caught the Chechen's glance derisive./ He grinned but did not say a word". 
Como alegoria de um mundo em desagregação, a figura da quimera na narrativa de Carvalho é chave de leitura importante, já que, ao lado da noção de philia contida na ideia do kunak estrutura possíveis modos de interpretação do texto. Em uma determinada passagem do romance, Andrei lê uma reveladora carta deixada por Ruslan entre os lençóis da cama:

Quando eu era pequeno, viajando pelas montanhas com o meu pai, para conhecer a terra dos seus antepassados, passamos por uma casa onde havia nascido um animal que era dois sem ser nenhum. Uma égua dera à luz um potro no qual estavam misturados dois embriões. A isso chamam quimera, como depois eu ia aprender na faculdade. Era um animal estranho, parecia um potro, mas era outra coisa, dois fundidos num só, indistintos. Não conseguia ficar em pé. As quimeras são raras e os pastores nas montanhas as veem como portadoras de mau agouro, porque põem a reprodução num impasse, fazem da reprodução uma monstruosidade. Por isso, quando esses animais não morrem ao nascer, os próprios camponeses se encarregam de lhes dar um fim. Nas montanhas, todo homem tem um kunak, um amigo estrangeiro que o salvará da morte e que ele também tem a obrigação de salvar. Nenhum homem será completo enquanto não encontrar o seu kunak. Só então poderá seguir o próprio caminho em paz, sabendo que existe no mundo alguém, como ele, com quem ele pode contar na 
vida e na morte. As quimeras morrem para que sobreviva o pacto dos que não podem contar nem com Deus nem com os anjos. (CARVALHO, 2009, p.161)

As imagens-força do kunak e da quimera estruturam um entendimento alegórico das questões do mundo arregimentadas pela ficção. No campo literário, Carvalho subverte estratégias mercadológicas e midiáticas ao transformar um projeto comercial em trampolim para a discussão crítica dos rumos da sociedade hodierna. Carvalho dribla a encomenda de uma história de amor quando recusa a generalização e faz da obra reflexão crítica sobre o mundo em suas limitações e potencialidades. As imagens do kunak e da quimera estruturam um saber alegórico relevante, pois são dois modos de entrada privilegiados em $O$ filho da mãe. Roland Barthes (1987) dizia que a força de mathesis em ação faz o texto literário falar para além da mimesis, configurando um jogo, a semiosis: por meio dela, o discurso literário trapaceia com a língua, deforma a história oficial, arruína as pretensões de verdade.

Carvalho recupera a monstruosidade como tema essencial: o sujeito monstruoso é uma vítima sacrificial da barbárie e a prosa de $O$ filho da mãe acusa na modernidade o falso elogio do progresso exposta na ideia de mobilidade, pois deslocamento também implica trânsito de ideias, 
movimentos do corpo, circulação de crenças e valores e não somente circulação de mercadorias. Uma globalização humana deve se dissociar de uma globalização de fábula (SANTOS, 2000) que transita claudicante entre signos de progresso e barbárie.

O tema da mobilidade e da clausura se relaciona com a questão da experiência em um mundo degradado. Pois não seria $O$ filho da mãe um exemplar de um conjunto significativo de ficções que concentram suas preocupações nas vias e desvios de nosso mundo contemporâneo? Essas indagações requerem aprofundamentos teóricos sobre políticas de mercado e suas relações com o mundo da vida. Neste sentido, mobilidade, clausura e leitura alegórica compõem um espaço crítico produtivo. $\mathrm{O}$ trabalho crítico-cooperativo que se nutre do auxílio das Ciências Sociais é essencial à formação de uma ética renovada acerca das novas organizações planetárias. A manutenção de uma transdisciplina ronda "os pesquisadores que admitem a insuficiência da própria área se reúnem com outros departamentos e reformulam suas perguntas" (CANCLINI, 2016, p.43). Essa proposta é contemplada na ideia de literatura como lugar de passagem (HELENA, 2010; 2012), como discurso que diz saber de algo (BARTHES, 1987) e deve ser suplementado pelas respostas que tentamos dar 
a nossas inquietações. Nossas perguntas mostram nossas limitações, mas são elas que atestam a força do discurso literário e seu desejo impossível de representar a realidade do mundo.

\section{REFERÊNCIAS}

AGAMBEN, Giorgio (2010). O que é o contemporâneo? e outros ensaios. Vinícius Nicastro Honesko (Trad.). 2. Reimp. Chapecó, SC: Argos.

BAKHTIN, Mikhail (2018). Teoria do romance II: a estilística. Paulo Bezerra (Trad.). São Paulo: Editora 34, p.10-45; 71-90.

(2015). Teoria do romance I: a estilística. Paulo Bezerra (Trad.). São Paulo: Editora 34, p.17-166.

BARTHES, Roland. (1987). Aula. Leyla Perrone-Moisés (Trad.). 4.ed. São Paulo: Cultrix.

BAUMAN, Zygmunt (2013). Vigilância líquida: diálogos com David Lyon. Carlos Alberto Medeiros (Trad.). Rio de Janeiro: Zahar.

(2001). Modernidade líquida. Plínio Dentzien (Trad.). Rio de Janeiro: Zahar.

(1999). Globalização: as consequências humanas. Marcus Penchel (Trad.). Rio de Janeiro: Zahar.

(1998). O mal-estar na pós-modernidade. Mauro Gama; Cláudia Martinelli Gama (Trad.). Rio de Janeiro: Zahar.

BENJAMIN, Walter (2012). "Experiência e pobreza”. In: .O anjo da história. João Barrento (Org. e Trad.). Belo Horizonte: Autêntica Editora, p.85-90.

(2011). Origem do drama trágico alemão. João Barrento (Trad.). Belo Horizonte: Autêntica.

(1985). "Sobre o conceito de história". In: . Magia e técnica, arte e política. Sérgio Paulo Rouanet (Trad.). 4.ed. São Paulo: Brasiliense.

CANCLINI, Nestor García (2016). O mundo inteiro como lugar estranho. Larissa Fostinone Locoselli (Trad.). São Paulo: EDUSP. 
CARVALHO, Bernardo (2009). O filho da mãe. São Paulo: Companhia das Letras.

DEFOE, Daniel (s/d.). Moll Flanders. New York: The Modern Library. HELENA, Lucia (2012). Náufragos da esperança: a literatura na época da incerteza. Rio de Janeiro: Oficina Raquel.

(2010). Fiç̧ões do desassossego: fragmentos da solidão contemporânea. Rio de Janeiro: Contra Capa.

HOBSBAWN, Eric (2013). Nações e nacionalismo desde 1780: programa, mito e realidade. Maria Célia Paoli; Anna Maria Quirino (Trad.). 6.ed. São Paulo: Paz e Terra.

LEAVITT, David (1998). "The term paper artist". In Arkansas. London: Abacus.

LERMONTOV, Mikhail Yurevitch (s/d). The demon: a poem. Alexander Condie Stephen (Trad.). Charleston, SC: BiblioLife.

(2014). Valerik. In http://rickrozoff.wordpress.com/2012/08/26/ mikhail-lermontov-still-youre-fighting-why-what-for Acesso em 13.Dez.2018.

(2009). A hero of our time. London: Penguin.

LIEVEN, Anatol (2010). "Chapter one". In: Chechnya: tombstone of Russian power. In http://www.nytimes.com/books/first/l/lievenchechnya.html Acesso em 13.Dez.2018.

OLIVEIRA, Paulo César Silva de (2011). "Representações da Guerra da Tchetchênia, em $O$ filho da mãe, de Bernardo Carvalho". Terra Roxa e outras Terras: Revista de Estudos Literários, 21, Londrina, PR, Universidade Estadual de Londrina, 101 - 112. In http://www.uel.br/pos/ letras/terraroxa/g_pdf/vol21/TRvol21i.pdf Acesso em 13.Dez.2018.

(2011). "Viagens reais e imaginárias: história, ficção e literatura hoje". Locus: revista de história, 17(1). Juiz de Fora, MG: Editora UFJF, 3962. In http://locus.ufjf.emnuvens.com.br/locus/article/view/1525 Acesso em 13.Dez.2018. 
(2012). "Um domínio do realismo na ficção de Bernardo Carvalho". Revista Escrita: revista (14), Rio de Janeiro: PUC-Rio, p.1-14. In http://www.maxwell.vrac.puc-rio.br/20012/20012.pdf Acesso em 13.Dez.2018.

(2010). Poéticas da distensão: entre a transcrição da paisagem e a escritura do caminho: crítica e desconstrução no Grande sertão: veredas, de Guimarães Rosa. Manaus: Edições Muiraquitã.

PERRONE-MOISÉS, Leyla (2007). Vira e mexe, nacionalismo: paradoxos do nacionalismo brasileiro. São Paulo: Companhia das Letras.

SANTOS, Milton (2000). Por uma outra globalização: do pensamento único ao pensamento universal. Rio de Janeiro: Record.

Paulo César Silva de Oliveira é Doutor em Letras (Ciência da Literatura) pela UFRJ e Pós-doutor em Estudos de Literatura pela UFF. Professor Adjunto IV de Teoria Literária na Faculdade de Formação de Professores da UERJ (FFP/UERJ) e Coordenador-Adjunto do Mestrado em Estudos Literários do Programa de Pós-Graduação em Letras e Linguística (PPLIN) da FFP/UERJ. Vice-líder dos Grupos de Pesquisa CNPq "Nação e Narração" e "Poéticas da diversidade". Autor de Poéticas da distensão (Manaus: Muiraquitã, 2010) e Uma literatura inquieta, em coautoria com Lucia Helena (Rio de Janeiro: Caetés, 2016). É bolsista do Programa de Incentivo à Produção Científica, Técnica e Artística - PROCIÊNCIA (UERJ/FAPERJ) e Bolsista de Produtividade em Pesquisa do CNPq. 